\title{
Common fixed point and invariant approximation results
}

\section{Marwan A Kutbi*}

\section{"Correspondence:}

mkutbi@yahoo.com

Department of Mathematics, King

Abdul Aziz University, P.O. Box

80203, Jeddah, 21589, Saudi Arabia

\begin{abstract}
Some common fixed point results for Banach operator pairs in strongly $M$-starshaped metric spaces are obtained. As application, invariant approximation theorems are derived.

MSC: $47 \mathrm{H} 10 ; 54 \mathrm{H} 25$

Keywords: common fixed point; Banach operator pair; strongly M-starshaped metric space; invariant approximation
\end{abstract}

\section{Introduction and preliminaries}

We first review needed definitions. Let $X$ be a metric space with metric $d, M \subset X$ and $J=[0,1]$. The space $X$ is called

(1) $M$-starshaped [1] if there exists a continuous mapping $W: X \times M \times J \rightarrow X$ satisfying

$$
d(x, W(y, q, \lambda)) \leq \lambda d(x, y)+(1-\lambda) d(x, q)
$$

for all $x, y \in X, q \in M$ and all $\lambda \in J$;

(2) strongly $M$-starshaped [2,3] if it is $M$-starshaped and satisfies the property $(I)$, that is,

$$
d(W(x, q, \lambda), W(y, q, \lambda)) \leq \lambda d(x, y)
$$

for all $x, y \in X, q \in M$ and all $\lambda \in J$;

(3) (strongly) convex if it is (strongly) $X$-starshaped;

(4) starshaped if it is $\{q\}$-starshaped for some $q \in X$.

A strongly convex metric space is also said to be a metric space of hyperbolic type (see Ciric [4]). Obviously, every normed space $X$ is a strongly convex metric space with $W$ defined by $W(x, q, \lambda)=\lambda x+(1-\lambda) q$ for all $x, q \in X$ and all $\lambda \in J$. More generally, if $X$ is a linear space with a translation invariant metric satisfying $d(\lambda x+(1-\lambda) y, 0) \leq \lambda d(x, 0)+(1-\lambda) d(y, 0)$, then $X$ is a strongly convex metric space. A subset $D$ of an $M$-starshaped metric space $X$ is called $q$-starshaped if there exists $q \in D \cap M$ such that $W(x, q, \lambda) \in D$ for all $x \in D$ and all $\lambda \in J$. For details, we refer the reader to Al-Thagafi [2], Guay et al. [5] and Takahashi [1].

Let $I, T: X \rightarrow X$ be two mappings and $D \subset X$. Then $T$ is called

(5) $I$-nonexpansive on $D$ if $d(T x, T y) \leq d(I x, I y)$ for all $x, y \in D$;

(6) $I$-contraction on $D$ if there exists $k \in[0,1)$ such that $d(T x, T y) \leq k d(I x, I y)$ for all $x, y \in D$.

( 2013 Kutbi; licensee Springer. This is an Open Access article distributed under the terms of the Creative Commons Attribution License (http://creativecommons.org/licenses/by/2.0), which permits unrestricted use, distribution, and reproduction in any medium, provided the original work is properly cited. 
A point $x \in D$ is a coincidence point (common fixed point) of $I$ and $T$ if $I x=T x$ $(x=I x=T x)$. The set of coincidence points of $I$ and $T$ is denoted by $C(I, T)$. The mappings $I$ and $T$ are called

(7) commuting on $D$ if $I T x=T I x$ for all $x \in D$;

(8) weakly compatible if they commute at their coincidence points, i.e., if $I T x=T I x$ whenever $I x=T x$.

The ordered pair $(I, T)$ of two self-maps of a metric space $X$ is called a Banach operator pair if the set $\operatorname{Fix}(T)$ is $I$-invariant, namely $I(\operatorname{Fix}(T)) \subseteq \operatorname{Fix}(T)$. Obviously, a commuting pair $(I, T)$ is a Banach operator pair but not conversely in general, see [6-8].

Let $S \subset X$ and $\widehat{x} \in X$. Then $P_{S}(\widehat{x})=\{x \in S: d(x, \widehat{x})=d(\widehat{x}, S)\}$ is called the set of best $S$ approximants to $\widehat{x}$, where $d(\widehat{x}, S)=\inf \{d(\widehat{x}, y): y \in S\}$ and $C_{S}^{I}(\widehat{x})=\left\{x \in S: I x \in P_{S}(\widehat{x})\right\}$.

In 1963, Meinardus [9] employed the Schauder fixed point theorem to prove a result regarding invariant approximation. In 1979, Singh [10] proved the following extension of the result of Meinardus.

Theorem 1.1 Let $T$ be a nonexpansive operator on a normed space $X$, let $M$ be a nonempty subset of $X, T(M) \subset M$ and $u \in F(T)$. If $P_{M}(u)$ is nonempty compact and starshaped, then $P_{M}(u) \cap F(T) \neq \emptyset$.

Hicks and Humphries [11] found that Singh's results remain true if $T(M) \subset M$ is replaced by $T(\partial M) \subset M$. In 1988, Sahab et al. [12] established the following result which contains the result of Hicks and Humphries and Theorem 1.1.

Theorem 1.2 Let I and $T$ be self-maps of a normed space $X$ with $u \in F(I) \cap F(T), M \subset X$ with $T(\partial M) \subset M$, and $q \in F(I)$. If $D=P_{M}(u)$ is compact and q-starshaped, $I(D)=D, I$ is continuous and linear on $D, I$ and $T$ are commuting on $D$ and $T$ is $I$-nonexpansive on $D \cup\{u\}$, then $P_{M}(u) \cap F(T) \cap F(I) \neq \emptyset$.

Invariant approximation results for commuting maps due to Al-Thagafi [13] extended and generalized Theorems 1.1-1.2 and the works of [11, 14, 15]. Al-Thagafi results were further extended by $[7,8,16-26]$ to $R$-subweakly commuting, pointwise $R$-subweakly commuting and a Banach operator pair.

The aim of this paper is to establish certain common fixed point theorem for a Banach operator pair in the setup of strongly $M$-starshaped metric spaces. As application, invariant approximation results for this class of maps are derived. Our results extend and unify the work of Al-Thagafi [2,13], Dotson [27], Habiniak [14], Hicks and Humphries [11], Hussain and Berinde [28], Hussain et al. [22], Naz [3], Latif [29], Sahab et al. [12] and Singh $[10,15]$.

The following result will be needed.

Lemma 1.3 [2] Let D be a subset of an M-starshaped metric space $(X, d)$ and $\widehat{x} \in X$. Then $P_{D}(\widehat{x}) \subset \partial D \cap D$.

\section{Main results}

The following result will be needed (see Lemma 2.10 [7] and Lemma 2.2 [8]). 
Lemma 2.1 Let $S$ be a nonempty subset of a metric space $(X, d)$, and let $T, f$ be self-maps of S. If $F(f)$ is nonempty, $c l T(F(f)) \subseteq F(f), c l(T(M))$ is complete, and $T$ and $f$ satisfy for all $x, y \in S$ and $0 \leq h<1$,

$$
d(T x, T y) \leq h \max \{d(f x, f y), d(T x, f x), d(T y, f y), d(T x, f y), d(T y, f x)\},
$$

then $S \cap F(T) \cap F(f)$ is a singleton.

Theorem 2.2 Let $S$ be a nonempty subset of a strongly $M$-starshaped metric space $X$ and let $T, f$ be self-maps of $S$. Suppose that $F(f)$ is q-starshaped, $c l T(F(f)) \subseteq F(f), c l(T(S))$ is compact, $T$ is continuous on $S$ and

$$
\begin{aligned}
\|T x-T y\| \leq & \max \{\|f x-f y\|, \operatorname{dist}(f x,[q, T x]), \operatorname{dist}(f y,[q, T y]), \\
& \operatorname{dist}(f y,[q, T x]), \operatorname{dist}(f x,[q, T y])\},
\end{aligned}
$$

for all $x, y \in S$, then $S \cap F(T) \cap F(f) \neq \emptyset$.

Proof Define $T_{n}: F(f) \rightarrow F(f)$ by $T_{n} x=W\left(T x, q, k_{n}\right)$ for all $x \in F(f)$ and a fixed sequence of real numbers $k_{n}\left(0<k_{n}<1\right)$ converging to 1 . Since $F(f)$ is $q$-starshaped and $c l T(F(f)) \subseteq$ $F(f)$, therefore $c l T_{n}(F(f)) \subseteq F(f)$ for each $n \geq 1$. Also, by (2.2),

$$
\begin{aligned}
d\left(T_{n} x, T_{n} y\right)= & d\left(W\left(T x, q, k_{n}\right), W\left(T y, q, k_{n}\right)\right) \\
= & k_{n} d(T x, T y) \\
\leq & k_{n} \max \{d(f x, f y), \operatorname{dist}(f x,[q, T x]), \operatorname{dist}(f y,[q, T y]), \\
& \operatorname{dist}(f x,[q, T y]), \operatorname{dist}(f y,[q, T x])\} \\
\leq & k_{n} \max \left\{d(f x, f y), d\left(f x, T_{n} x\right), d\left(f y, T_{n} y\right), d\left(f y, T_{n} x\right), d\left(f x, T_{n} y\right)\right\}
\end{aligned}
$$

for each $x, y \in F(f)$ and $0<k_{n}<1$. If $c l(T(S))$ is compact for each $n \geq 1$, then $c l\left(T_{n}(S)\right)$ is compact and hence complete. By Lemma 2.1, for each $n \geq 1$, there exists $x_{n} \in F(f)$ such that $x_{n}=f x_{n}=T_{n} x_{n}$. The compactness of $c l(T(M))$ implies that there exists a subsequence $\left\{T x_{m}\right\}$ of $\left\{T x_{n}\right\}$ such that $T x_{m} \rightarrow z \in \operatorname{cl}(T(M))$ as $m \rightarrow \infty$. Since $\left\{T x_{m}\right\}$ is a sequence in $T(F(f))$ and $c l T(F(f)) \subseteq F(f)$, therefore $z \in F(f)$. Further, $x_{m}=T_{m} x_{m}=W\left(T x_{m}, q, k_{m}\right) \rightarrow z$. By the continuity of $T$, we obtain $T z=z=f z$. Thus, $S \cap F(T) \cap F(f) \neq \emptyset$.

Corollary 2.3 Let $S$ be a nonempty subset of a strongly M-starshaped metric space $X$ and let $T, f$ be self-maps of $S$. Suppose that $F(f)$ is q-starshaped, $c l T(F(f)) \subseteq F(f), c l(T(S))$ is compact, $T$ is continuous on $S$ and $T$ is $f$-nonexpansive on $S$, then $S \cap F(T) \cap F(f) \neq \emptyset$.

Corollary 2.4 Let $S$ be a nonempty subset of a strongly $M$-starshaped metric space $X$ and let $T, f$ be self-maps of $S$. Suppose that $F(f)$ is closed and q-starshaped, $(T, f)$ is a Banach operator pair, cl( $T(S))$ is compact, $T$ is continuous on $S$ and $T$ satisfies (2.2) or $T$ is $f$-nonexpansive on $S$, then $S \cap F(T) \cap F(f) \neq \emptyset$.

Corollary 2.5 ([13], Theorem 2.1) Let $M$ be a nonempty closed and q-starshaped subset of a normed space $X$ and let $T$ and $f$ be self-maps of $M$ such that $T(M) \subseteq f(M)$. Suppose that 
$T$ commutes with $f$ and $q \in F(f)$. If $c l(T(M))$ is compact, $f$ is continuous and linear and $T$ is $f$-nonexpansive on $M$, then $M \cap F(T) \cap F(f) \neq \emptyset$.

Corollary 2.6 (([30], Theorem 3.3)) Let $M$ be a nonempty subset of a normed space $X$ and let $T$ and $f$ be self-maps of $M$. Suppose that $F(f)$ is q-starshaped, $c l T(F(f)) \subseteq F(f), c l(T(M))$ is compact, $T$ is continuous on $M$ and (2.2) holds for all $x, y \in M$. Then $M \cap F(T) \cap F(f) \neq \emptyset$.

Corollary 2.7 ([7], Theorem 2.11) Let M be a nonempty subset of a normed space $X$ and let $T, f$ be self-maps of $M$. Suppose that $F(f)$ is q-starshaped and closed cl $(T(M))$ is compact, $T$ is continuous on $M,(T, f)$ is a Banach operator pair and satisfies (2.2) for all $x, y \in M$. Then $M \cap F(T) \cap F(f) \neq \emptyset$.

Corollary 2.8 Let $X$ be a strongly M-starshaped metric space, let $f, T: X \rightarrow X$ be two mappings, $S$ be a subset of $X$ such that $T(\partial S \cap S) \subset S$ and $\widehat{x} \in F(T) \cap F(f)$. Suppose that $P_{S}(\widehat{x})$ is nonempty closed and $q$-starshaped with $q \in F(f) \cap M$ and $c l\left(T\left(P_{S}(\widehat{x})\right)\right)$ is compact and $f\left(P_{S}(\widehat{x})\right)=P_{S}(\widehat{x})$. If T is continuous, $c l T(F(f)) \subseteq F(f)$ and satisfies, for all $x \in P_{S}(\widehat{x}) \cup\{\widehat{x}\}$,

$$
d(T x, T y) \leq \begin{cases}d(f x, f u) & \text { if } y=u, \\ \max \{d(f x, f y), \operatorname{dist}(f x,[q, T x]), \operatorname{dist}(f y,[q, T y]), & \\ \operatorname{dist}(f x,[q, T y]), \operatorname{dist}(f y,[q, T x])\} & \text { if } y \in P_{S}(\widehat{x}),\end{cases}
$$

then $P_{S}(\widehat{x}) \cap F(T) \cap F(f) \neq \emptyset$.

Proof Let $x \in P_{S}(\widehat{x})$. Then by Lemma 1.3, $x \in \partial S \cap S$ and so $T x \in S$ since $T(\partial S \cap S) \subset S$. As $T$ satisfies $(2.3)$ on $P_{S}(\widehat{x}) \cup\{\widehat{x}\}$ and $I\left(P_{S}(\widehat{x})\right)=P_{S}(\widehat{x})$, we have

$$
d(T x, \widehat{x})=d(T x, T \widehat{x}) \leq d(I x, \widehat{x})=d(I x, \widehat{x})=d(\widehat{x}, S) .
$$

This implies that $T x \in P_{S}(\widehat{x})$. Thus $T\left(P_{S}(\widehat{x})\right) \subset P_{S}(\widehat{x})=f\left(P_{S}(\widehat{x})\right)$. Now Theorem 2.2 implies that $P_{S}(\widehat{x}) \cap F(T) \cap F(f) \neq \emptyset$.

Theorem 2.9 Let $X$ be a strongly $M$-starshaped metric space, letf, $T: X \rightarrow X$ be two mappings, $S$ be a subset of $X$ such that $T(\partial S \cap S) \subset S$ and $\widehat{x} \in F(T) \cap F(f)$. Suppose that $P_{S}(\widehat{x})$ is nonempty closed and $q$-starshaped with $q \in F(f) \cap M$ and $c l\left(T\left(P_{S}(\widehat{x})\right)\right)$ is compact and $f\left(P_{S}(\widehat{x})\right)=P_{S}(\widehat{x})$.If $T$ is continuous, $\operatorname{cl} T(F(f)) \subseteq F(f)$ and $T$ is $f$-nonexpansive on $P_{S}(\widehat{x}) \cup\{\widehat{x}\}$, then $P_{S}(\widehat{x}) \cap F(T) \cap F(f) \neq \emptyset$.

Remark 2.10 A subset $S$ of a strongly $M$-starshaped metric space $X$ is said to have the property $(N)$ w.r.t. $T[22,28]$ if

(i) $T: S \rightarrow S$,

(ii) $W\left(T x, q, k_{n}\right) \in S$ for some $q \in S \cap M$ and a fixed sequence of real numbers $k_{n}$ $\left(0<k_{n}<1\right)$ converging to 1 and for each $x \in S$.

All results of the paper (Theorem 2.2-Theorem 2.9) remain valid provided $f$ is assumed to be surjective and $q$-starshapedness of the set $F(f)$ is replaced by the property $(N)$ respectively. Consequently, recent results due to Hussain and Berinde [28] and Hussain et al. [22] are improved and extended. 
Remark 2.11 Recently, in [31], the author obtained certain fixed point theorems in convex metric spaces. Using Theorems 3.2 and 3.4 [31] and the technique in [7], we can prove more common fixed point and approximation results for Banach pairs satisfying generalized nonexpansive conditions in a strongly $M$-starshaped metric space $X$.

Remark 2.12 All results of the paper can be proved for multivalued Banach operator pairs defined and studied in [32].

\section{Competing interests}

The author declares that he has no competing interests.

\section{Authors' contributions}

The author has read and approved the final manuscript.

\section{Acknowledgements}

This research was funded by the Deanship of Scientific Research (DSR), King Abdulaziz University, Jeddah. The author acknowledges with thanks DSR, KAU for financial support.

Received: 25 November 2012 Accepted: 7 May 2013 Published: 27 May 2013

\section{References}

1. Takahashi, W: A convexity in metric spaces and non-expansive mappings I. Kodai Math. Semin. Rep. 22, 142-149 (1970)

2. Al-Thagafi, MA: Best approximation and fixed points in strong M-starshaped metric spaces. Int. J. Math. Math. Sci. 18, 613-616 (1995)

3. Naz, A: Best approximation in strongly M-starshaped metric spaces. Rad. Mat. 10, 203-207 (2001)

4. Ciric, LB: Contractive type non-self mappings on metric spaces of hyperbolic type. J. Math. Anal. Appl. 317, 28-42 (2006)

5. Guay, MD, Singh, KL, Whitfield, JHM: Fixed point theorems for nonexpansive mappings in convex metric spaces. In: Singh, SP, Burry, JH (eds.) Proc. Conf. on Nonlinear Analysis, vol. 80, pp. 179-189. Dekker, New York (1992)

6. Chen, J, Li, Z: Common fixed points for Banach operator pairs in best approximation. J. Math. Anal. Appl. 336, 1466-1475 (2007)

7. Hussain, $\mathrm{N}$ : Common fixed points in best approximation for Banach operator pairs with Ćirić type /-contractions. J. Math. Anal. Appl. 338, 1351-1363 (2008)

8. Khan, AR, Akbar, F: Best simultaneous approximations, asymptotically nonexpansive mappings and variational inequalities in Banach spaces. J. Math. Anal. Appl. 354, 469-477 (2009)

9. Meinardus, G: Invarianze bei linearen approximationen. Arch. Ration. Mech. Anal. 14, 301-303 (1963)

10. Singh, SP: An application of fixed point theorem to approximation theory. J. Approx. Theory 25, $89-90$ (1979)

11. Hicks, TL, Humphries, MD: A note on fixed point theorems. J. Approx. Theory 34, 221-225 (1982)

12. Sahab, SA, Khan, MS, Sessa, S: A result in best approximation theory. J. Approx. Theory 55, 349-351 (1988)

13. Al-Thagafi, MA: Common fixed points and best approximation. J. Approx. Theory 85, 318-323 (1996)

14. Habiniak, L: Fixed point theorems and invariant approximations. J. Approx. Theory 56, $241-244$ (1989)

15. Singh, SP: Applications of fixed point theorems in approximation theory. In: Lakshmikantham, V (ed.) Applied Nonlinear Analysis, pp. 389-394. Academic Press, New York (1979)

16. Akbar, F, Khan, AR: Common fixed point and approximation results for noncommuting maps on locally convex spaces. Fixed Point Theory Appl. 2009, Article ID 207503 (2009)

17. Ciric, LB, Hussain, N, Akbar, F, Ume, JS: Common fixed points for Banach operator pairs from the set of best approximations. Bull. Belg. Math. Soc. Simon Stevin 16, 319-336 (2009)

18. Ćirić, LB, Hussain, N, Cakic, N: Common fixed points for Ciric type $f$-weak contraction with applications. Publ. Math. (Debr.) 76(1-2), 31-49 (2010)

19. Hussain, N: Asymptotically pseudo-contractions, Banach operator pairs and best simultaneous approximations. Fixed Point Theory Appl. 2011, Article ID 812813 (2011)

20. Hussain, N, Khamsi, MA, Latif, A: Banach operator pairs and common fixed points in hyperconvex metric spaces. Nonlinear Anal. 74, 5956-5961 (2011)

21. Hussain, N, Pathak, HK: Subweakly biased pairs and Jungck contractions with applications. Numer. Funct. Anal. Optim. 32(10), 1067-1082 (2011)

22. Hussain, N, O'Regan, D, Agarwal, RP: Common fixed point and invariant approximation results on non-starshaped domains. Georgian Math. J. 12, 659-669 (2005)

23. Hussain, N, Rhoades, BE: $C_{q}$-commuting maps and invariant approximations. Fixed Point Theory Appl. 2006, Article ID $24543(2006)$

24. O'Regan, D, Hussain, N: Generalized /-contractions and pointwise R-subweakly commuting maps. Acta Math. Sin. Engl. Ser. 23, 1505-1508 (2007)

25. Khan, AR, Akbar, F: Common fixed points from best simultaneous approximations. Taiwan. J. Math. 13(5), 1379-1386 (2009)

26. Pathak, HK, Hussain, N: Common fixed points for Banach operator pairs with applications. Nonlinear Anal. 69 2788-2802 (2008) 
27. Dotson, WJ Jr.: Fixed point theorems for nonexpansive mappings on star-shaped subsets of Banach spaces. J. Lond Math. Soc. 4, 408-410 (1972)

28. Hussain, N, Berinde, V: Common fixed point and invariant approximation results in certain metrizable topological vector spaces. Fixed Point Theory Appl. 2006, Article ID 23582 (2006)

29. Latif, A: A result on best approximation in p-normed spaces. Arch. Math. 37, 71-75 (2001)

30. Al-Thagafi, MA, Shahzad, N: Banach operator pairs, common fixed points, invariant approximations and *-nonexpansive multimaps. Nonlinear Anal. 69, 2733-2739 (2008)

31. Moosaei, M: Fixed point theorems in convex metric spaces. Fixed Point Theory Appl. 2012, Article ID 164 (2012)

32. Espínola, R, Hussain, N: Common fixed points for multimaps in metric spaces. Fixed Point Theory Appl. 2010, Article ID $204981(2010)$

doi:10.1186/1687-1812-2013-135

Cite this article as: Kutbi: Common fixed point and invariant approximation results. Fixed Point Theory and Applications $20132013: 135$

\section{Submit your manuscript to a SpringerOpen ${ }^{\circ}$ journal and benefit from:}

- Convenient online submission

- Rigorous peer review

- Immediate publication on acceptance

- Open access: articles freely available online

- High visibility within the field

- Retaining the copyright to your article 